\title{
Special Requirements of Mind Mapping Software for English Learning
}

\author{
Bin Gui ${ }^{1, a}$ and Xiaotian Wang ${ }^{1, b^{*}}$ \\ ${ }^{1}$ School of Humanity and Law, Beijing University of Civil Engineering and Architecture, Beijing, \\ 100044 P.R. China \\ ${ }^{2}$ Department of Art Media, Hainan College of Software Technology, Qionghai, 571400, P.R. China \\ a373229248@qq.com, ${ }^{*}$ hljjxwxt521@126.com \\ *The corresponding author
}

Keywords: Mind maps; English learning software; English thinking

\begin{abstract}
Mind mapping plays an important role in the learning and training English vocabulary, reading and writing English. In the learning of English through mind maps, a mind map with relevant learning content is to be drawn via the mind mapping software, but current graphics have many drawbacks and deficiencies. This paper discusses the special requirements of the mind mapping software for English learning and provides a good idea for upgrading mind mapping software and developing new software.
\end{abstract}

\section{Introduction}

Mind Map was invented by Tony Buzan in 1960s and has been gaining worldwide popularity at a staggering rate. A mind map is a polychromatic image centered radial diagram that represents semantic connections among portions of learned material. It is a new and effective way of organising one's thoughts. It is a powerful graphic technique which provides a universal key to unlock your brain's potential.

A mind map represents semantic or other connections between portions of information. By presenting these connections in a radial, non-linear graphical manner, it encourages a brainstorming approach to any given organizational task, forming a structure that is easy to understand and remember. It is used to generate, visualize, structure and classify ideas, and as an aid in study, organization, problem solving, and decision making. It harnesses the full range of cortical skills - word, image, number, logic, rhythm, color and spatial awareness - in a single, uniquely powerful manner.

Computer Mind Maps offer several major advantages over the original paper Mind Map. You can easily restructure your Mind Map, moving words and trees of words around in seconds. This makes the computer Mind Map even better for quickly creating new ideas and ordering ideas into a meaningful structure. Using the style system you can instantly highlight different features of a complex Mind Map. With a computer Mind Map you can instantly export the Mind Map to a normal text file or to a structured word processor document.

Mind map has been applied widely and successfully in many fields. And a few researches have been done about mind map and applying mind map to Computer, Reading, Information Technology, Design and Development and so on. At present, mind mapping software still have many shortcomings and deficiencies. It was discussed that Mind mapping software is required for special functions on English language learning. The research ideas are provided for upgrading mind mapping software and developing new software[1,2,3].

\section{Brief Introduction of Mind Mapping Software}

The development of mind map is represented in some software. With the development of computer technology, there are various kinds of mind map software, such as BrainMine, Inspiration, MindManager, MindManuals, MindMapper, SmartDraw, MindGenius, Mind Visualizer and etc. But 
Mindmanager and Mindmapper are most frequently used. With the help of software, mind maps can be easily drawn on computer, which could make the information and data more and more visual and meaning can be expressed more clearly.

iMindMap is a creative and easily-used tool that is available in three Editions. It is the only software that accurately delivers the visual flexibility and brain friendliness of the highly proven and renown Buzan Mind Mapping techniques. iMindMap allows you to organise, create, innovate, plan, present, notate, learn, structure, communicate, solve problem and project manage all in one place. The Elements Edition offers a truly organic Mind Mapping experience using the tools and techniques developed by Tony Buzan whose process has been successfully used by millions of people world-wide, and is ideal for all your basic Mind Mapping needs. As an effective tool, mind map software with multiple versions has been being.

\section{Special Requirements of Mind Mapping Software for English Learning}

Although there are many mind mapping software, they have a lot of obvious weaknesses. Such as the graphics bases are too simple to collect a small number of graphics. Furthermore, three-dimensional graphics are less, most graphs are flat. There is no three-dimensional mind map templates.Therefore, demand is not met for display mind mapping of brain's thought imagine.

Especially in learning English, English thought is needed in order to free from the impact of the mother tongue. The central theme and segment synopsis of entire text can not be prompted to rely on Chinese words and ideas. Instead of simply reading entire text on some topics, next time try to use a Mind Map while you read. Just draw your central word and then begin reading, every time you read some idea that strikes you as important or interesting, just add it to your Mind Map in the appropriate place in English. When you have finished reading the text, you will have a one page Mind Map that summarizes every interesting things in that text. You will probably also have added several things that you thought up yourself during your reading.

The act of creating the Mind Map will have greatly increased how much you absorbed from the text, and if you ever want to review the topic, all you need to do is to look at the Mind Map. If you want to learn the information more solidly, then try to redraw the Mind Map from memory a few times. You will find it very easy.

In order to better achieve the exploitation of right-brain, English thought has been trained by the help of Mind Mapping. We made a number of ideas for Mind Mapping, in order to provide good idea in the designing of the next generation of mind maps.

Problem of Graphics Bases. Graphics bases construct of Mind mapping software is the most urgent requirements, graphics bases should be significantly abundant in the future of designing mind mapping software. And there should be a scientific classification. Planar or three-dimensional graphics bases can be established, graphics bases can also be classified according to subject such as geometry, chemistry, physics and Biology graphics, etc. Stick figure bases can also be established based on a Stick figure of the salient features. Cartoon bases can also be established in order to increase interest of mind mapping software.

The Establishment of Intelligent Drawing Template. The next generation mind mapping software have graphics bases to be assorted completely, but no matter how many graphics in graphics bases, they can not cover all the graphics. Therefore, we need to design an intelligent drawing template. Painting template enriched function of the graphics bases. Even if we ask the graphics are not in the graphics library. Even if we do not have the drawing basic skills, we can draw ourselves required graphics by using intelligent drawing template. For example, to design intelligent stick figure template, this template should have such a function. That is, we draw a person in the template, even though the portrait is dissatisfied, but this software can automatically fix this portrait as a pretty standard person. By using intelligent drawing template, as long as we draw an outline of a squatting person, and in accordance with the guidance function of the software, the software will automatically form a squatting portraits required, such as men, women, youth or boys and so on.

Compatibility and Search of Graphics. If the software provides a greatly enriched graphics 
bases, because a large number of graphics, the software search function be required to provide a picture for a particular topic. In addition to mind mapping software provides intelligent drawing templates, the software should also be compatible with the present or future mapping software.

\section{Conclusion}

Mind maps can help us to learn English,it can help us to remember English words, it can help us to improve the reading and writing ability $[4,5]$. In particular, it can help us train our English thinking ability, English has been greatly improved. We have put forward some ideas that can be implemented in the mind map. On the mind mapping software, we have put forward some ideas that can be technically achieved. The next generation of mind mapping software, it will absorb the essence of existing mapping software, function of the software will produce a great leap forward. Mind mapping attract more and more people's attention, there is a very broad application prospects in English learning.

\section{Acknowledgements}

This research was supported by the Hainan Provincial Planning of Philosophy and Social Sciences under Grant HNSK (YB) 16-87.

\section{References}

[1] T. Buzen, B. Buzen. The MindMap Book: How to Use Radiant Thinking to Maximize Your Brain's Untapped Potential. New York: Plume, 1993.

[2] T. Buzen. The MindMap - A Radiant Thinking. Beijing: World books publication company, 2004.

[3] T. Buzen. The MindMap . Translation by Li Si, Beijing: Writers Publishing House, 1999.

[4] C. Zhang. Mind mapping analysis on English reading teaching. Journal of Chengdu College of Education, 19(2005):76-78.

[5] X. Y. Shu. An Experiment Research of Application of MindMap into English Writing Teaching. Journal of Harbin University, 3(2009): 116-121. 